\title{
SERUM TESTOSTERONE IN MALES WITH NEWLY DIAGNOSED TYPE 2 DIABETES MELLITUS AND MICROVASCULAR COMPLICATIONS
}

\author{
Bajaj $\mathbf{S}^{1}$, Srivastava $\mathbf{A}^{1}$, Varma $\mathbf{A}^{1}$, Tiwari $\mathbf{A}^{1}$ \\ ${ }^{1}$ Department of Medicine, MLN Medical College, Allahabad.
}

\begin{abstract}
Background: The role of testosterone in the pathogenesis of metabolic syndrome and diabetes mellitus has been well documented. Low testosterone levels have been associated with an increased risk of insulin resistance and type 2 diabetes mellitus (T2DM) and testosterone supplementation has been found to reduce insulin resistance and blood glucose levels. However, there is limited data available regarding the influence of testosterone levels on microvascular complications in patients with diabetes. This study was undertaken with the objective of evaluating levels of serum testosterone in newly diagnosed male patients with T2DM and to correlate serum testosterone levels with microvascular complications.
\end{abstract}

Materials and Methods: A single point cross sectional case-control study was conducted at MLN Medical College, Allahabad and its associated SRN Hospital, Allahabad from March 2013 to July 2014. 168 males between 18-60 years of age were recruited for the study. From these patients, 83 patients who were diagnosed with T2DM during the last 3 months were considered as cases and remaining 85 patients without diabetes were taken as controls. Detailed history was obtained and clinical examination was performed. Serum low testosterone was defined as total testosterone $<241 \mathrm{ng} / \mathrm{dl}$ and the prevalence of its deficiency was calculated. The values of serum testosterone were correlated with microvascular complications of diabetes viz. neuropathy, retinopathy and nephropathy.

Results: Out of the 83 patients of T2DM, low serum testosterone was found in $37(44.58 \%)$ while it was present in only $10(11.8 \%)$ of 85 controls, which was statistically significant $\left(\chi^{2}=20.84\right.$, df $\left.=1, \mathrm{p}<0.0001\right)$. Microvascular complications were seen in $25(67.56 \%$ ) patients with low testosterone while only $4(8.7 \%)$ patients had microvascular complications with normal testosterone level which was statistically significant $(\mathrm{p}<0.0001)$.

Conclusions: Prevalence of hypogonadism was significantly $(\mathrm{P}<0.0001)$ higher in T2DM patients compared to controls. Subjective evidence of hypogonadism and microvascular complications were observed more frequently in patients with low testosterone compared to normal testosterone.

Key words: newly diagnosed type 2 diabetes, serum testosterone, hypogonadism, microvascular complications.

\section{INTRODUCTION}

In recent years, studies have shown an inverse relationship between testosterone with metabolic syndrome as well as T2DM (1). Testosterone has been found to play a significant role in obesity, glucose homeostasis, and lipid metabolism. Cross-sectional epidemiological studies have reported a direct correlation between plasma testosterone and insulin sensitivity (2), and low testosterone levels have been associated with an increased risk of T2DM, which has been illustrated by androgen deprivation in men with prostate carcinoma (3). Several studies have suggested that men with low testosterone are at a greater risk of developing T2DM and may even predict the onset of diabetes (4-8). A systematic review of 43 studies including 6427 men by Ding, et al suggested that higher plasma levels of testosterone were associated with lower risk of T2DM and vice versa (9). Similarly, Haffner et al demonstrated that low sex hormone-binding globulin (SHBG) and testosterone levels are associated with higher glucose and insulin levels and increased obesity (8). Osuna et al correlated waist circumference, body mass index
(BMI), insulin, and homeostatic model assessment of insulin resistance (HOMA-IR) to testosterone levels and, in each case, found a significant negative correlation with all these parameters (10). These findings when taken together, raise the possibility that testosterone may be having a protective function against the development of diabetes mellitus in men.

Testosterone replacement has been found to reverse some parts of the unfavourable risk profile for the development of diabetes mellitus and atherosclerosis in hypogonadal males (11). Fukui et al demonstrated that serum testosterone levels are lower in a large number of Japanese patients with T2DM when compared with healthy men and testosterone supplementation could decrease insulin resistance (IR) and atherosclerosis in these hypogonadal males (12). Boyanov et al also showed that men with T2DM receiving three months of testosterone supplementation had decreased fasting glucose, postprandial glucose, mean daily glucose and HbA1c values, compared with baseline in men with T2DM (13). Kapoor et al have also reported that 
testosterone treatment in insulin-dependent hypogonadal patients improved the glycaemic control and reduced their insulin dosages by a mean of seven units (14). Naharci et al also had demonstrated that long term testosterone therapy can improve the insulin sensitivity and body composition parameters, especially the body fat mass (15).

Many male patients with T2DM are likely to have evidence of hypogonadism at the time of diagnosis, which has an important bearing on the disease pathogenesis as well as the quality of life of the individual. However, the implications of low testosterone levels of these men on complications of diabetes are largely unknown. The objective of this study was to assess the testosterone levels in newly diagnosed male patients with T2DM and to assess any correlation with microvascular complications.

\section{METHODS}

This case-control study was conducted on 168 subjects at MLN Medical College, Allahabad and its associated SRN Hospital, Allahabad from March 2013 to July 2014. 168 male subjects between 18-60 years of age were recruited for the study. Of these 168 subjects, 83 were T2DM who were diagnosed during the last 3 months, according to the 2012 American Diabetes Association guidelines and were considered as study subjects, either admitted to SRN Hospital or attending Medicine OPD. Rest of the 85 individuals were age and BMI matched non-diabetic healthy male volunteers who were considered for the control group. Patients with type 1 diabetes mellitus, those who were on hormone replacement therapy (steroids or testosterone), patients with chronic renal or hepatic disease, HIV infection, surgically uncorrected cryptorchidism, malignancy and the patients who were on chemotherapeutic agents or radiation therapy, prior infectious orchitis and those in whom surgical orchiectomy was done, were excluded from the study.

A detailed history, clinical examination and investigations were done in each patient in order to assess disease severity, its microvascular complications and severity of hypogonadism. History taking included symptoms of neuropathy, past history of hypertension and use of anti-hypertensive medications. The ADAM (Androgen Deprivation in Ageing Male) questionnaire (Table 1).was used to score the severity of hypogonadism. Diabetic neuropathy was deemed to be present if the patient complained of any symptom of neuropathy after ruling out other disorders that can cause neuropathy on the basis of history and clinical examination. Examination of deep tendon reflexes, $10 \mathrm{~g}$ monofilament test, vibration and proprioception sense were used to find out the presence of neuropathy. Indirect ophthalmoscopy was used to screen diabetic retinopathy. Non-hypertensive patients with diabetes mellitus were screened for nephropathy with urine microalbumin test and heat coagulation tests. Serum testosterone levels (morning sample) were estimated using chemiluminescence immunoassay. Low testosterone was defined as serum total testosterone level $<241 \mathrm{ng} / \mathrm{dl}$ and the prevalence of its deficiency was calculated. Informed consent was taken from all the participants in the study.

\section{Table 1: Androgen Deprivation in the Aging Male (ADAM) Questionnaire}

\section{Yes} No

1. Do you have a decrease in libido (sex drive)?

2. Do you have a lack of energy?

3. Do you have a decrease in strength and/or endurance?

4. Have you lost height?

5. Have you noticed a decreased "enjoyment of life"?

6. Are you sad and/or grumpy?

7. Are your erections less strong?

8. Have you noticed a recent deterioration in your ability to play sports?

9. Are you falling asleep after dinner?

10. Has there been a recent deterioration in your work performance? 
Table 2: Distribution of testosterone deficiency in different age categories

\begin{tabular}{|c|c|c|c|c|}
\hline \multirow[t]{2}{*}{ Age (years) } & \multicolumn{2}{|c|}{ Cases } & \multicolumn{2}{|c|}{ Controls } \\
\hline & $\begin{array}{c}\text { Low testosterone } \\
\text { n }(\%)\end{array}$ & $\begin{array}{c}\text { Normal testosterone } \\
\mathrm{n}(\%)\end{array}$ & $\begin{array}{c}\text { Low testosterone } \\
\text { n ( } \%)\end{array}$ & $\begin{array}{c}\text { Normal testosterone } \\
\text { n }(\%)\end{array}$ \\
\hline$\leq 30$ & $1(2.7 \%)$ & $2(4.3 \%)$ & $1(10 \%)$ & $5(6.7 \%)$ \\
\hline $31-40$ & $6(16.2 \%)$ & $8(17.4 \%)$ & $2(20 \%)$ & $13(17.3 \%)$ \\
\hline $41-50$ & $16(43.2 \%)$ & $24(52.2 \%)$ & $3(30 \%)$ & $34(45.3 \%)$ \\
\hline $51-60$ & $14(37.9 \%)$ & $12(26.1 \%)$ & $4(40 \%)$ & $23(30.7 \%)$ \\
\hline Total & 37 & 46 & 10 & 75 \\
\hline
\end{tabular}

\section{Table 3: Serum testosterone in the study group and the control group}

\begin{tabular}{|c|c|c|c|}
\hline Testosterone category & Study group $(n=83)$ & Control group $(n=85)$ & $\mathrm{p}$ \\
\hline Low testosterone & $37(44.58 \%)$ & $10(11.8 \%)$ & $<0.0001$ \\
\hline Normal testosterone & $46(55.42 \%)$ & $75(82.2 \%)$ & \\
\hline
\end{tabular}

The relationship between serum testosterone levels and microvascular complications of diabetes mellitus was evaluated. Continuous variables were compared using ' $\mathrm{t}$ ' test for independent variables and Chi-square test was applied on categorical variables.

\section{RESULTS}

Table 2 shows distribution of serum testosterone deficiency among cases and controls. Lower testosterone levels were observed at a younger age in patients with diabetes compared to non-diabetic healthy volunteers (Table 2).

Out of the 83 patients of T2DM, low serum testosterone levels were found in $37(44.58 \%)$ while low levels were present only in $10(11.8 \%)$ of 85 controls, which was found to be statistically significant $(\chi 2=20.84, \mathrm{df}=1, p<0.0001)$ (Table 3). The mean serum testosterone levels in study subjects were significantly lower compared to control group $(254.99 \pm 154.15 \mathrm{ng} / \mathrm{dl}$ vs. $360.66 \pm 120.74 \mathrm{ng} / \mathrm{dl}$, CI 95\%, t $=4.9529$, df $=166, p<0.0001)$.

The response to ADAM questionnaire was more frequently positive in patients with low testosterone levels $(89.2 \%$; $p<0.0001)$ compared to study patients with normal testosterone levels (Table 4).

Microvascular complications were more prevalent among the study patients with low testosterone levels compared to the study patients with normal testosterone levels $(p<0.0001)$ as depicted in Table 5.

\section{DISCUSSION}

Testosterone deficiency is more prevalent in newly diagnosed T2DM patients compared to non-diabetic patients. More positive results with ADAM questionnaire were found in patients with low testosterone. In patients with diabetes, low testosterone levels seem to have positive correlation with the incidence of microvascular complications of diabetes.

Serum testosterone level tends to decline with age by approximately $0.5-2 \%$ per year which seems to be a normal aging process of men. This observation has been confirmed by several previous studies $(6,16,17,18,19)$. Low testosterone levels are common in patients with T2DM. Hayek et al. found that $36.5 \%$ of patients with T2DM had testosterone levels $<300 \mathrm{ng} / \mathrm{dl}$ and $29 \% \mathrm{had}$ symptoms of androgen deficiency (20). Kapoor et al. showed that $20 \%$ of men with diabetes have testosterone levels <230 ng/dl and 31\% have levels between 230-346 $\mathrm{ng} / \mathrm{dl}(20)$. Grossman et al have shown similar results where $43 \%$ of men with T2DM had low testosterone levels $(<288 \mathrm{ng} / \mathrm{dl})$, which increased up to $61 \%$ in men who were 80 years or older (22).

Testosterone biosynthesis is regulated primarily by pulsatile secretion of $\mathrm{LH}$ and the serum levels reflect the integrity of the hypothalamic-pituitary-gonadal (HPG) axis. Low testosterone levels noted in cases of insulin resistance may indicate a defect at one or more functional levels of the HPG axis. In a background of insulin-resistance, Leydig cell function, particularly steroidogenesis, may be impaired by changes in the production of hormones and 
Table 4: Distribution of response to ADAM questionnaire among patients in the study group patients

\begin{tabular}{|c|c|c|c|}
\hline ADAM questionnaire & Low $T(n=37)$ & Normal T $(n=46)$ & $\mathrm{p}$ \\
\hline Positive & $33(89.2 \%)$ & $1(2.1 \%)$ & $<0.0001$ \\
\hline Negative & $4(10.8 \%)$ & $45(97.9 \%)$ & \\
\hline
\end{tabular}

Table 5: Distribution of microvascular complications

\begin{tabular}{|c|c|c|c|}
\hline $\begin{array}{l}\text { Microvascular } \\
\text { complications }\end{array}$ & Low $T(n=37)$ & Normal T $(n=46)$ & $\mathrm{p}$ \\
\hline Present & $25(67.56 \%)$ & $4(8.7 \%)$ & $<0.0001$ \\
\hline Absent & $12(32.44 \%)$ & $42(91.3 \%)$ & \\
\hline
\end{tabular}

cytokines locally in the target tissue and in adipose tissue. Although the studies suggest that increasing insulin resistance may be attributed to a decrease in testosterone secretion in men, it is not fully clear as to how the HPG axis mediates the interplay between testosterone and insulin levels. Other potential mechanisms for low testosterone levels in T2DM include reduced or absent stimulatory effect of insulin on Leydig cells and Leydig cell dysfunction and steroid biosynthesis inhibition by increase leptin and TNF levels.

The ADAM questionnaire was positive more frequently in patients with low testosterone levels $(89.2 \%)$ and this difference was statistically significant $(\mathrm{P}<0.0001)$. This suggests that majority of males with newly diagnosed T2DM had evidence of symptomatic hypogonadism at the time of diagnosis. Using the definition of hypogonadism as the combination of symptoms (positive ADAM score) in addition to a low testosterone level, Kapoor et al demonstrated that $17 \%$ of the patients with T2DM have overt hypogonadism with a total testosterone $<230 \mathrm{ng} / \mathrm{dl}$ and $25 \%$ patients have possible hypogonadism with total testosterone between 230-346 ng/dl (21).

Present study demonstrated a significantly higher percentage of patients with symptomatic hypogonadism. This could be a unique phenomenon demonstrated in South Asian genotype that needs further research.

Diabetes mellitus is strongly associated with microvascular complications such as neuropathy, retinopathy and nephropathy resulting in organ and tissue damage and these complications are seen in approximately one-third to one-half of people with the disease (23). There has been a significant correlation between the microvascular complications and the testosterone level of these patients and this association has been strongest with diabetic neuropathy $(12,22,24)$. This study also demonstrated a significant correlation with low serum testosterone levels and the presence of diabetes related microvascular complications (neuropathy in $59.46 \%$, retinopathy in $27 \%$ and nephropathy in $21.62 \%$ ) with a stronger association with diabetic neuropathy.

The main strength of this study is its matched casecontrol design, which is controlled for age and BMI by design and analysis that minimized the bias due to confounders. However, cross sectional design made it difficult to determine whether diabetes was preceded or followed by the decline in serum testosterone levels. This effect was minimized by recruiting newly diagnosed patients with diabetes. Due to the effect of circadian rhythm, the pulsatile nature of its secretion, use of concomitant medications and measurement variations, the testosterone level can vary and a single testosterone value could have been inadequate for making a diagnosis of hypogonadism. Free testosterone values are known to represent the actual evidence of hypogonadism. Due to the inaccuracy of conventional methods in assessing free testosterone levels, free levels were not estimated and had to rely on total testosterone levels. Furthermore, the cross sectional design limits the ability to assess causality. Due to the time constraints and the stringent selection criteria, the sample size was small and generalization of the results was a problem.

\section{CONCLUSIONS}

Prevalence of hypogonadism is significantly higher in newly diagnosed T2DM patients compared to controls.

Subjective evidence of hypogonadism using ADAM questionnaire is seen more commonly in patients with low testosterone compared to those with normal levels. 
Microvascular complications are seen more frequently in hypogonad males with T2DM. Screening of hypogonadism at the time of diagnosis may have important clinical implications with regards to the complications of diabetes and the quality of individual's life.

\section{REFERENCES}

1. Saad F and Gooren LJ. The role of testosterone in the etiology and treatment of obesity, the metabolic syndrome, and diabetes mellitus type 2 . Journal of Obesity. 2011; 19: 471-584.

2. Pitteloud N, Mootha VK, Dwyer AA, Hardin M, Lee H, Groop L et al. Relationship between testosterone levels, insulin sensitivity, and mitochondrial function in men. Diabetes Care. 2005; 28: 1636-1642.

3. Basaria S, Muller DC, Carducci MA, Egan J, Dobs AS et al. Hyperglycemia and insulin resistance in men with prostate carcinoma who receive androgen-deprivation therapy. Cancer 2006; 106: 581-588.

4. Stellato RK, Feldman HA, Hamdy O, Horton ES, McKinlay JB. Testosterone, sex hormone-binding globulin, and the development of type 2 diabetes in middle-aged men: prospective results from the Massachusetts male aging study. Diabetes Care. 2000; 23: 490-494.

5. Oh JY, Barrett-Connor E, Wedick NM, Wingard DL. Endogenous sex hormones and the development of type 2 diabetes in older men and women; the Rancho Bernardo study. Diabetes Care. 2002; 25: 55-60.

6. Rhoden EL, Ribeiro EP, Teloken C, Souto CAV. Diabetes mellitus is associated with subnormal serum levels of free testosterone in men. British Journal of Urology International. 2005; 96: 867-870.

7. Grundy SM, Cleeman JI, Daniels SR, Donato KA, Eckel $\mathrm{RH}$, Franklin BA. Diagnosis and management of the metabolic syndrome an American Heart Association/National Heart, Lung, and Blood Institute scientific statement. Circulation. 2005; 112: 2735 2752.

8. Haffner SM, Shaten J, Stem MP, Smith GD, Kuller L and MRFIT Research Group. Low levels of sex hormone-binding globulin and testosterone predict the development of non-insulin-dependent diabetes mellitus in men. MRFIT Research Group. Multiple Risk Factor Intervention Trial. American Journal of Epidemiology. 1996; 143: 889-97.

9. Ding EL, Song Y, Malik VS, Liu S. Sex differences of endogenous sex hormones and risk of type 2 diabetes: a systematic review and meta-analysis. Journal of American Medical Association 2006; 295: 1288-1299.

10. Osuna JA, Gomez-Perez R, Arata-Bellabarba G et al. Relationship between BMI, total testosterone, sex hormonebinding-globulin, leptin, insulin and insulin resistance in obese men. Arch Androl. 2006; 52: 355-361.

11. Heufelder AE, Saad F, Gooren L, Bunck MC. Fiftytwo-Week Treatment With Diet and Exercise Plus Transdermal Testosterone Reverses the Metabolic Syndrome and Improves Glycemic Control in Men With Newly Diagnosed Type 2 Diabetes and Subnormal Plasma Testosterone. Journal of Andrology. 2009; 30: 726733.

12. Fukui M, Soh J, Tanaka M, Kitagawa Y, Hasegawa G, Yoshikawa T et al. Low serum testosterone concentration in middle-aged men with type 2 diabetes. Endocrine Journal. 2007; 54: 871-877.

13. Boyanov MA, Boneva $\mathrm{Z}$ and Christov VG. Testosterone supplementation in men with type 2 diabetes, visceral obesity and parital androgen deficiency. Aging Male. 2003; 6: 1-7.

14. Kapoor D, Goodwin E, Channer KS, Jones TH. Testosterone replacement therapy improves insulin resistance, glycaemic control visceral adiposity and hypercholesterolaemia in hypogonadal men with type 2 diabetes. European Journal of Endocrinology. 2006; 154: 899-906.

15. Naharci MI, Pinar M, Bolu E, Olgun A. Effect of testosterone on insulin sensitivity in men with idiopathic hypogonadotropic hypogonadism. Endocrine Practice. 2007; 13: 629-635.

16. Dhindsa S, Prabhakar S, Sethi M, Bandyopadhyay A, Chaudhuri A, Dandona P. Frequent occurrence of hypogonadotropic hypogonadism in type 2 diabetes. Journal of Clinical Endocrinology and Metabolism. 2004; 89:5462-5468.

17. Corona G, Mannucci E, Petrone L, Ricca V, Balercia $G$, Mansani R et al. Association of hypogonadism and type II diabetes in men attending an outpatient erectile dysfunction clinic. International Journal of Impotence Research. 2006; 18: 190-197.

18. Selvin E, Feinleib M, Zhang L, Rohrmann S, Rifai N, Nelson WG, et al. Androgens and diabetes in men. Diabetes Care. 2007; 30: 234-238.

19. V Kupelian, ST Page, AB Araujo, Travison TG, Bremner WJ, McKinlay JB. Low sex hormone-binding globulin, total testosterone, and symptomatic androgen deficiency are associated with development of the metabolic syndrome in non-obese men. Journal of Clinical Endocrinology and Metabolism. 2006; 91: 843-850.

20. Hayek AAA, Khader YS, Jafal S, Khawaja N, Robert AA, Ajlouni K. Prevalence of low testosterone levels in men with type 2 diabetes mellitus: a cross $^{-}$sectional study. Journal of Family and Community Medicine. 2013; 20: 179-186.

21. Kapoor D, Aldred H, Clark S, Channer KS, Jones TH. Clinical and biochemical assessment of hypogonadism in men with type 2 diabetes. Diabetes Care. 2007; 30: 911-917.

22. Grossman M, Thomas MC, Panagiotopoulos S, Sharpe K, Maclsaac RJ, Clarke S et al. Low testosterone levels are common and associated with insulin resistance in men with diabetes. Journal of Clinical Endocrinology and Metabolism. 2008; 93: 18341840.

23. United Kingdom prospective diabetes study (UKPDS) 13: relative efficacy of randomly allocated diet, sulphonylurea, insulin or metformin in patients with newly diagnosed non-insulin dependent diabetes followed for three years. British Medical Journal. 1995; 310: 83-88.

24. Ali ST, Shaikh RN, Ashfaqsiddiqi N, Siddiqi PQ. Serum and Urinary levels of pituitary: Gonadal hormones in insulin-dependent and non-insulindependent diabetic males with and without neuropathy. Arch Androl. 1998; 30: 117-123. 